\title{
Evaluation on the Development Levels of the Low-carbon Cities in Hunan Province Based on AHP and TOPSIS
}

\author{
Yuxiang Yang ${ }^{1, a}$ \\ ${ }^{1}$ Department of economics and management, Hengyang Normal University, Hengyang Hunan \\ 421002, China \\ aoyx626@163.com
}

\begin{abstract}
Keywords: Low-carbon City; AHP (analytic hierarchy process); TOPSIS (Technique for Order Preference by Similarity to Ideal Solution).
\end{abstract}

\begin{abstract}
The AHP(analytic hierarchy process) and TOPSIS (Technique for Order Preference by Similarity to Ideal Solution) are applied to evaluate low-carbon urban development level of 14 prefecture-level cities in Hunan province. These methods not only have various advantages of analytic hierarchy process and maintain original quantitative values of evaluation indexes during evaluation so that evaluation result is more scientific, objective and impartial, which have an important significance to promote sustainable development of a city.
\end{abstract}

\section{Introduction}

A city is the center of human production and life where over half of the world's population gathers; emission of greenhouse gas caused by its activities accounts for over $75 \%$ of the total. Recently, Hunan rapidly develops in urbanization and industrialization, urban expansion speed is increasingly fast, the developing mode of traditional industrial civilization brings enormous pressure to energy, resources, environment and other material elements; low-carbon economy is an inevitable choice during future development[1]. Evaluation of low-carbon urban development is helpful to implement development strategy of low-carbon urban construction, enhance future competitiveness of a city, build a livable city and realize sustainable development[2].

At present, numerous methods can be used for evaluation of low-carbon city, such as the Delphi method, comprehensive index method, analytic hierarchy process, grey system method, ideal solution and others, every has its advantages and has been applied to different fields, a certain effect has been achieved. Technique for order preference by similarity to ideal solution (TOPSIS) is an effective multi-index evaluation method and maintains original quantitative indicators through sorting accessibility of various evolution objects and ideal targets; it is flexible and simple for use, however, the disadvantage is that weights of evaluation indexes cannot be determined; Analytic hierarchy process (AHP) is an efficient tool used for determining weight of multi-levels and multi-factors, but its disadvantage is that all indicators are measured through relative importance set by subjectivity; accuracy of evolution can be reduced to some extent. Combination of TOPSIS and AHP is used to evaluate low-carbon city which can absorb advantages of two methods and perfect shortcomings; advantages of analytic hierarchy process can be kept and at the same time original quantitative index values can be used to improve operability of evaluation method and scientificity, authenticity and comprehensiveness of evaluation results.

\section{The Comprehensive Evaluation of the Development Levels of the Low-carbon Cities}

General procedures of applying the AHP and TOPSIS to evaluation are shown as following: firstly, multi-level comprehensive evaluation index system shall be established; then the AHP and TOPSIS shall be combined and the closeness degree of different regions shall be calculated; finally the closeness degree of different regions will be sorted by size; if a city has maximum closeness degree, it has highest level of low carbon development. 


\section{The Establishment of the evaluation model}

AHP is used for layering of low carbon development level evaluation; namely, according to general objectives of low-carbon development, problems affecting development of a low-carbon city are decomposed into different factors. Combining with trial index system of a low-carbon city construction issued by the state environmental protection administration and according to scientific and comparability principles, systemic and hierarchical principles, pertinence and operability principles and $3 \mathrm{R}$ principle of a low carbon city evaluation, prefecture-level low-carbon urban evaluation index system in Hunan province is formed, its framework are shown in table 1.

Table 1 The hierarchical structure chart of the evaluation index system of low-carbon cities

\begin{tabular}{|c|c|c|}
\hline Target Level & Criterion Level & Index Level \\
\hline \multirow{20}{*}{$\begin{array}{l}\text { Low Carbon } \\
\text { Economic } \\
\text { Development } \\
\text { Level A }\end{array}$} & \multirow{5}{*}{ Economic Development B1 } & GDP per Capita \\
\hline & & Disposable income of urban residents \\
\hline & & Net income of rural residents \\
\hline & & The third industry output value accounted for GDP \\
\hline & & The second industry output value accounted for GDP \\
\hline & \multirow{3}{*}{$\begin{array}{c}\text { Low Carbon } \\
\text { Energy Consumption } \\
\text { B2 }\end{array}$} & Energy Consumption per Unit of GDP \\
\hline & & Carbon Emission per Unit of GDP \\
\hline & & $\mathrm{SO}_{2}$ of per Unit of GDP \\
\hline & \multirow{4}{*}{ Social Support B3 } & The Amount of Buses Possessed per Million People \\
\hline & & Urbanization Rate \\
\hline & & The Engel coefficient \\
\hline & & Ownership of private cars per hundred \\
\hline & \multirow{5}{*}{$\begin{array}{l}\text { Low Carbon Technology } \\
\text { B4 }\end{array}$} & The Ratio of R\&D Funds accounted for GDP \\
\hline & & the Utilization Rate of Industrial Waste \\
\hline & & Centralized Sewage Treatment Rate \\
\hline & & Attainment rate of the industrial waste water \\
\hline & & Living garbage harmless treatment rate \\
\hline & \multirow{3}{*}{ Natural Environment B5 } & The forest coverage rate \\
\hline & & Greenbelt area per capita \\
\hline & & Greenbelt area coverage rate of built area \\
\hline
\end{tabular}

From table1, it can concluded that the frame including three levels of index, criterion and goal which are subordinated layer by layer. Thereinto, the goal level is the general performance of the prefecture-level cities in Hunan Province to develop the low-carbon cities; the criterion level includes the five aspects of economic development, low-carbon consumption, social supports, low-carbon technologies and natural environment; the basic index which is used to reflect the criterion level and processed after calculation is the index level.

\section{The Determination of Index Weights}

When evaluating the development levels of the low-carbon cities, each evaluation index in the evaluation index system has different influences on the subsystems. In order to represent the differences, the relevant weights shall be given to the evaluation indexes before the comprehensive evaluation. The paper adopts AHP which is commonly used in evaluating the current low-carbon development to determine the index weights, and the steps are as follows:

Form the judgment matrix. The highest level is objective layer in table 1, that is comprehensive performance of prefecture-level cities of Hunan province in low-carbon urban development; The second level is criterion layer including five elements of economic development B1, low-carbon energy consumption B2, society supporting B3, low-carbon technology B4 and natural environment B5; corresponding weights at the first level are respectively $\mathrm{U} 1, \mathrm{U} 2, \mathrm{U} 3, \mathrm{U} 4$ and $\mathrm{U} 5$ and $\sum U_{i}=1$; if vector quantity of ranking weight of criterion layer relative to objective layer is $\mathrm{V}$, there is $V=\left(\mathrm{U}_{1}, \mathrm{U}_{2}, \mathrm{U}_{3}, \mathrm{U}_{4}, \mathrm{U}_{5}\right)^{T}$, where, $\mathrm{T}$ is transposition. According to professional advice of respondents, pairwise comparison of relative importance B1, B2, B3, B4 and B5, judgment 
matrix $A$ is established, $A=\left[a_{i j}\right]_{5^{*}}$. Where, $a_{i j}$ means quantitative expression of importance of ration of $B_{i}$ and $B_{j}$ compared with objective criterion; its value shall be in accordance with importance values provided at proportional scale table of table 2[3].

Table 2 Saaty Proportional Scaling Table

\begin{tabular}{|l|l|l|l|l|l|l|}
\hline Factor i \& Factor j & $\begin{array}{l}\text { Equally } \\
\text { important }\end{array}$ & $\begin{array}{l}\text { Slightly } \\
\text { important }\end{array}$ & $\begin{array}{l}\text { Quite } \\
\text { important }\end{array}$ & $\begin{array}{l}\text { Strongly } \\
\text { important }\end{array}$ & $\begin{array}{l}\text { Extremely } \\
\text { important }\end{array}$ & $\begin{array}{l}\text { The median of two } \\
\text { neighboring judgments }\end{array}$ \\
\hline Quantitative value & 1 & 3 & 5 & 7 & 9 & $2,4,6,8$ \\
\hline
\end{tabular}

Calculate the weight vectors of judgment matrix. Firstly, judgment matrix is normalized with column orientation; Then normalized matrix is added according to line, a vector quantity can be obtained by normalization with column orientation and get the vector $W_{i}$; finally, $L W_{i}$, a proper vector of judgment matrix $\mathrm{A}$ is calculated; namely, judgment matrix times $W_{i}$.

Judge the consistency of judgment matrix. For reasonableness of $L W_{i}$, consistency check shall be carried out, steps are shown as below: firstly, maximum latent root of judgment matrix according to equation (1); Then consistency index is calculated according to equation (2); consistency ratio is calculated according to equation (3) (where, C.I. is consistency index and R.I. is random consistency index; they can be obtained by query in table 3). Finally, consistency shall be judged. If C.R. $\leq 0.1$ is met, it is thought that the consistency of judgment matrix is satisfactory by judgment. Otherwise, adjustment shall be conducted to judge scale value of judgment matrix again until judgment matrix has satisfactory consistency.

$$
\begin{aligned}
& \lambda_{\max }=\frac{1}{n} \sum \frac{L W_{i}}{W_{i}} \\
& \text { C.I. }=\frac{\lambda_{\max }-n}{n-1} \\
& \text { C.R. }=\frac{\text { C.I. }}{\text { R.I. }}
\end{aligned}
$$

Table 3 The standard values of the mean random consistency indexes

\begin{tabular}{|c|c|c|c|c|c|c|c|c|c|c|}
\hline matrix order & 1 & 2 & 3 & 4 & 5 & 6 & 7 & 8 & 9 & 10 \\
\hline R.I. & 0 & 0 & 0.58 & 0.90 & 1.12 & 1.24 & 1.32 & 1.41 & 1.45 & 1.49 \\
\hline
\end{tabular}

Determine the weight of each hierarchy. In accordance with the above method, the weights of economic development, social support, low-carbon energy consumption, low-carbon technology and natural environment are respectively $0.271,0.056,0.223,0.267$ and 0.181 and the weight vector is $\mathrm{A}$ $=(0.27,0.06,0.27,0.06$ and 0.18$)$. Similarly, weight vectors of GDP per capita and urban residents' disposable income, rural residents' disposable income, output value ratio of tertiary industry accounting for GDP, output value ratio of the second industry accounting for GDP can be obtained; they are $(0.29,0.16,0.15,0.15,0.25)$; Weight vectors of energy consumption per unit of GDP, carbon emissions per unit of GDP and $\mathrm{SO}_{2}$ emission per unit of GDP are $(0.49,0.28,0.23)$, Weight vectors of bus number owned by every ten thousand people, urbanization rate, Engel coefficient and private car number owned by every one hundred people are $(0.36,0.14,0.14,0.36)$; Weight vectors of $R \& D$ funds ratio accounting for GDP, utilization rate of industrial waste and sewage concentrated processing rate, industrial wastewater treatment rate up to the standard and hazard-free treatment rate of household garbage are $(0.25,0.24,0.24,0.14,0.13)$; Weight vectors of forest coverage rate, green area per capita, forest coverage rate of built-up area are $(0.34,0.33,0.33)$.

\section{The Comprehensive Application of AHP-TOPSIS}

Sample data of all indexes for economic development can be obtained by looking up Hunan Statistical Yearbook (in 2013)[4], national economic and social development statistical bulletin in 2013 of prefecture-level cities of Hunan province and Hunan statistical information network and reverse indexes are converted into positive indexes by inverse method and judgment matrix $X_{1}^{(1)}$ is 
constructed (Omission):

Original data of GDP per capita and urban residents' disposable income, rural residents' disposable income, output value ratio of tertiary industry accounting for GDP, output value ratio of the second industry accounting for GDP at Changsha, Zhuzhou, Xiangtan, Hengyang, Shaoyang, Yueyang, Changde, Zhangjiajie, Yiyang, Chenzhou, Yongzhou, Huaihua, Loudi, Xiangxi autonomous prefecture is successively shown at every line. $X_{1}^{(1)}$ is normalized by linear scale converter technique and then standardization decision matrix $Y_{1}^{(1)}$ can be obtained; $Y_{1}^{(1)}$ is weighted by using weights $(0.29,0.16,0.15,0.15$ and 0.25$)$ obtained above by AHP and weighted standardization evaluation matrix can be obtained.

$$
V_{1}=\left(W_{j} Y_{1}^{(1)}\right)_{14 * 5}
$$

Weighted standardization evaluation matrix $V_{1}$ shall be calculated; positive ideal solution of $\mathrm{V}$ matrix is $V_{1}^{*}=(0.29,0.16,0.15,0.15,0.01)$ and negative ideal solution is $V_{1}^{-}=(0.29,0.16,0.15$, $0.15,0.01)$.

Distance of prefecture level cities and positive ideal solution $S^{*}$ and negative ideal solution $S^{-}$are calculated respectively according to formula (5) and it can be obtained that:

$$
\begin{aligned}
S_{1}^{*} & =0.26, S_{2}^{*}=0.20, S_{3}^{*}=0.19, S_{4}^{*}=0.22, S_{5}^{*}=0.93, S_{6}^{*}=0.22, S_{7}^{*}=0.23, S_{8}^{*}=0.87, S_{9}^{*}=0.75, S_{10}^{*}=0.76, S_{11}^{*}=0.81, \\
S_{12}^{*} & =0.85, S_{13}^{*}=0.91, S_{14}^{*}=0.90 \\
S_{1}^{-}= & 0.94, S_{2}^{-}=0.51, S_{3}^{-}=0.12, S_{4}^{-}=0.13, S_{5}^{-}=0.06, S_{6}^{-}=0.13, S_{7}^{-}=0.11, S_{8}^{-}=0.14, S_{9}^{-}=0.08, S_{10}^{-}=0.12, S_{11}^{-}=0.11 \\
S_{12}^{-}= & 0.09, S_{13}^{-}=0.09, S_{14}^{-}=0.112 \\
S_{i}^{*} & =\sqrt{\sum_{j=1}^{5}\left(V_{i j}-V_{j}^{*}\right)^{2}}, S^{-}=\sqrt{\sum_{j=1}^{5}\left(V_{i j}-V_{j}^{-}\right)^{2}}, i=1,2, \cdots \cdots, 14 \\
C_{i} & =\frac{S_{i}^{-}}{S_{i}^{+}+S_{i}^{-}}
\end{aligned}
$$

According to relative proximity formula(6), economic development index proximity of Changsha, Zhuzhou, Xiangtan, Hengyang, Shaoyang, Yueyang, Changde, Zhangjiajie, Yiyang, Chenzhou, Yongzhou, Huaihua, Loudi, Xiangxi autonomous prefecture is:

$$
\begin{aligned}
& C_{1}^{*}=0.78, C_{2}^{*}=0.72, C_{3}^{*}=0.38, C_{4}^{*}=0.37, C_{5}^{*}=0.06, C_{6}^{*}=0.37, C_{7}^{*}=0.33, C_{8}^{*}=0.13, C_{9}^{*}=0.09, C_{10}^{*}=0.14, C_{11}^{*}=0.12, \\
& C_{12}^{*}=0.09, C_{13}^{*}=0.09, S_{14}^{*}=0.12
\end{aligned}
$$

Similarly, proximity of low-carbon energy consumption index, social support index, low-carbon technology index and natural environment index of prefecture-level cities can be obtained.

Taking proximity of each criterion as decision matrix of objective layer, according to A weight, weighted processing is conducted, positive ideal solution and negative ideal solution, the relative proximity and ranking of low-carbon urban development level of 14 prefecture-level cities in Hunan province can be obtained (If $\mathrm{Ci}$ is bigger, it indicates that the $\mathrm{i}$-th evaluation unit is closer to optimal level) as shown in table 4.

From table 4, it can be seen that Changsha is the best low-carbon development city; in recent years, after becoming a pilot (resource-economical and environment-friendly society), Changsha optimizes industrial structure, changes traditional economic development mode, develops circular economy and promotes economic cycle and efficient development through advanced low-carbon technology and others. Loudi is the worst low-carbon development city, main reasons are that it still is given priority to resource intensive industry and that industrial structure and energy consumption structure are not adjusted and optimized timely according to need of social and economic development and that development advantages of all aspects are not obvious. Because Zhangjiajie, Huaihua and others are tourist cities and there are few people at mountain areas and others, these cities take front place; Hengyang, as a traditional industrial city, strives to adjust economic structure and transform mode of economic development, uses development opportunity of economic transformation, vigorously advocates low-carbon economy, actively constructs low-carbon city and 
low-carbon society and some achievements have been obtained, especially Changsha-ZhuzhouXiangtan urban agglomeration can promote exchange and cooperation among cities, speed up internal economic structure transformation of three cities, strengthen energy conservation and promote low-carbon development construction by development pattern (integration) [5].

Table 4. The evaluation results of AHP-TOPSIS Method on the low-carbon cities in Hunan

\begin{tabular}{|c|c|c|c|c|}
\hline $\begin{array}{l}\text { Prefecture level } \\
\text { city }\end{array}$ & $\begin{array}{l}\text { the distance to positive } \\
\text { ideal solution }\end{array}$ & $\begin{array}{l}\text { the distance to negative } \\
\text { ideal solution }\end{array}$ & $\begin{array}{l}\text { the relative closeness } \\
\text { degrees }\end{array}$ & rankings \\
\hline Changsha & 0.127 & 0.307 & 0.707 & 1 \\
\hline Zhuzhou & 0.088 & 0.114 & 0.564 & 4 \\
\hline Xiangtan & 0.249 & 0.256 & 0.507 & 5 \\
\hline Hengyang & 0.051 & 0.065 & 0.56 & 12 \\
\hline Shaoyang & 0.083 & 0.059 & 0.413 & 8 \\
\hline Yueyang & 0.167 & 0.185 & 0.459 & 10 \\
\hline Changde & 0.292 & 0.248 & 0.603 & 2 \\
\hline Zhangjiajie & 0.048 & 0.073 & 0.439 & 11 \\
\hline Yiyang & 0.238 & 0.186 & 0.559 & 6 \\
\hline Chenzhou & 0.097 & 0.123 & 0.542 & 7 \\
\hline Yongzhou & 0.176 & 0.208 & 0.595 & 3 \\
\hline Huaihua & 0.087 & 0.128 & 0.386 & 14 \\
\hline Loudi & 0.227 & 0.143 & 0.408 & 13 \\
\hline $\begin{array}{c}\text { Xiangxi } \\
\text { Prefecture }\end{array}$ & 0.408 & 0.281 & & 5 \\
\hline
\end{tabular}

\section{Summary}

Low-carbon urban development evaluation is an important part of urban construction management, reasonable and scientific selection of evaluation method is of great significance to promote sustainable development of a city. AHP-TOPSIS is applied to evaluate low-carbon urban development, which not only has scientificity, comprehensiveness and objectivity and also can avoid disadvantages of other methods and increase accuracy of evaluation results and it will be rapidly popularized and applied in various management evaluation fields.

\section{Acknowledgement}

This project is sponsored by Hunan Social Science Fund (13YBA051), Hengyang Social Science Fund (2015D019), the research achievement of Hunan province key discipline of regional economics.

\section{References}

[1] Yundeng,FU.The Study of Low Carbon City Evaluation Method and Supporting System.Chinese Population Resource and Environment,2010(8)

[2] Xiaofang ZHANG:Research on the development of low carbon economy in Gansu Province Based on Fuzzy Analytic Hierarchy Process.Scientific \& Technical Information of Gansu:2014(3)

[3] Rongying ZENG.On Evaluating of Teaching and Research Section in Local University Based on AHP-TOPSIS.Journal of Hengyang Normal University:2015,36(3):p145-147

[4] Information on http://www.hntj.gov.cn/tjfx/tjgb_3399/hnsgmjjhshfztjgb/

[5] Dajian,ZHU. The Model of Urban Low Carbon Competitiveness Evaluation and The Empirical Study of The City of Shanghai. Modern Urban Study, 2011 (11)

[6] Guiyang, ZHUANG: The Connotation and The Construction of Comprehensive Evaluation Index System of Low Carbon Economy. The Trend of Economics:2011(1):p132-136 